\title{
METAL IONS CONTAMINATION IN GROUND WATER OF KATHMANDU AND REMOVAL OF IRON USING ADSORBENT PREPARED FROM NATURAL RESOURCES
}

\author{
Vinay Kumar J ha* and Ram Bahadur Khatri* \\ *Central Department of Chemistry, Tribhuvan University, Kirtipur, Kathmandu, Nepal.
}

\begin{abstract}
Some metal ions contaminations of underground water have been assessed in Kathmandu. A total of ten water samples, randomly collected from deep tube wells and shallow wells, were analyzed for metal ions by AAS. The comparison of the data of physico-chemical properties of contaminated ground water showed that $\mathrm{pH}$, sodium, potassium, zinc, lead and cadmium lie within the WHO guideline value for drinking water whereas, the concentration of iron was found to be higher in almost all underground water samples.

Adsorbents for Fe ion removal were prepared from various resources such as crab’s shell powder, silica stone powder, hen's eggshell powder and limestone powder. The adsorbent prepared from hen's eggshell was found appropriate and cost effective resource to remove Fe ions from aqueous solution and the maximum Fe ion adsorption capacity for such an adsorbent was $0.24 \mathrm{mg} / \mathrm{g}$. The Langmuir type adsorption isotherm was found to fit in the experimental data than the Freundlich isotherm.
\end{abstract}

Keywords: Underground water of Kathmandu valley; Fe adsorption; Eggshell powder; Langmuir adsorption isotherm.

\section{INTRODUCTION}

Kathmandu valley is believed to be a lake in pre-historic period. But later, it became suitable for human settlement and the civilization started in Kathmandu. With increase in population, the available water becomes insufficient and people started to search new sources by constructing well and stone spout. With time as the city grew, people faced the shortage of water. The river water was deteriorating due to haphazard urbanization and industrialization and the volume of required water decreased. In additional sealing of ground by buildings and roads decreased the ground water level consequently drying up the stone spouts, which was the major source of water in past. As a result water from different sources such as rivers; springs etc. were piped into the valley from periphery areas such as Sundarijal, Budhanilkantha, Dudhkhola, etc. But in dry season, these pipelines water cannot fulfill the water supply demand in Kathmandu valley. Thus, on an average the contribution of the ground water remains close to $50 \%$ of the total supply ${ }^{1}$.

Groundwater constitutes 1.7 percent (or 23.4 million $\mathrm{km}^{3}$ ) of the total 1.384 billion $\mathrm{km}^{3}$ water in earth ${ }^{2}$. Ground water is an important source of water for the inhabitant of the Kathmandu valley as majority of the residents depends on this source.

Water fit for drinking exists in the ground in some form at some depth nearly everywhere on earth. Ground water is generally better and safe as a source of drinking water than that of surface water due to the soil filtering mechanism. Traditionally, man has always extracted water from the ground through hand-dug wells. This method is supremely successful and has been used throughout the world for thousands of years. Ground water is very important source of water and in some areas it is the only source of water. Increasing demand for portable water has forced the growing use of ground water throughout the worlds.

There are four major sources of contamination in water. These are industrial, municipal, agricultural sectors and geological conditions.

Waste water discharged by industries that process ores and concentrates of non-ferrous metals is usually polluted with heavy metal ions, such as cadmium $\left(\mathrm{Cd}^{2+}\right)$, lead $\left(\mathrm{Pb}^{2+}\right)$, nickel $\left(\mathrm{Ni}^{2+}\right)$, copper $\left(\mathrm{Cu}^{2+}\right)$, zinc $\left(\mathrm{Zn}^{2+}\right)$, etc. Many industries involved in metal finishing, mining and mineral processing, coal mining and oil refining, have problems associated with heavy metal contamination of process and runoff waters. The development of new approaches and technologies is therefore needed, to assist in both the removal and recovery of valuable metals from process and wastewaters ${ }^{3}$.

Rural municipal wastewater consists most often of a combination of domestic and commercial wastewaters. The pollutant parameters commonly present are biological oxygen

Author for Correspondence: Vinay Kumar J ha, Central Department of Chemistry, Tribhuvan University, Kirtipur, Kathmandu, Nepal. E-mail: vinayj2@yahoo.com. 
demand, suspended solids, pathogens, ammonium, nitratenitrites, organic-nitrogen, inorganic phosphorous and organic phosphorous. Trace metals and organic pollutant molecules may also be present. Many stock farms are located in rural areas and livestock wastewaters are not always treated adequately. In addition, urea fertilizers and livestock manure are often spread onto the cropped fields. Therefore, intensive stock farming represents a potential source of contamination of groundwater in these areas ${ }^{4}$. Also, the traditional habit of people to use open fields and stream sides as latrines and the ignorance on their part to see the dangers following their action equally contribute to the water pollution.

Greater focus is being placed on the research into improving the quality of wastewater being released from above mentioned sources. In order for small rural municipalities, with lower tax bases and limited resources, to adopt wastewater treatments technologies, purifying techniques must be of low cost, require minimal maintenance, and be easily applicable 4 . Regular monitoring and surveillance from the standpoint of physical, chemical and microbiological standards should be needed to improve the quality of groundwater. The people should be made aware of their works, which they have done to increase water pollutions unknowingly.

The WHO standard for total iron plus manganese in drinking water is $0.3 \mathrm{mg} / \mathrm{L}^{5}$. The primary concern about the presence of iron in drinking water is its objectionable colour and taste. The taste of iron in drinking water can be easily detected even at low concentrations of about $1.8 \mathrm{mg} / \mathrm{L}$. Although iron metal is necessary for growth of plants and animals but after certain concentrations, it becomes poisonous.

Analytical works on water samples of spouts of Pashupati area have been reported and the average $\mathrm{pH}$, ammonia and iron values ranged from $6.3-6.5,<0.05-0.56 \mathrm{mg} / \mathrm{L}$ and 0.05 $0.84 \mathrm{mg} / \mathrm{L}$, respectively ${ }^{6}$. The average values for conductivity, hardness and chloride lie within the WHO permissible level. Likewise in 1992, the temperature and $\mathrm{pH}$ ranged from 21.4 $23.4^{\circ} \mathrm{C} \& 6.3-6.7$, respectively. Parameters like conductivity, hardness, chloride and turbidity were recorded within permissible level. Average values for iron and ammonia ranged from 0.2-1.9 mg/L and $<0.01-3.02 \mathrm{mg} / \mathrm{L}$, respectively.

The study of altogether 95 ground water samples were reported from various point of Kathmandu valleys and showed that ground water in Kathmandu valley is contaminated with iron and ammonia and to some extent manganese also. Presence of iron and ammonia in high concentration might have been due to geological condition? ${ }^{7}$.

The $\mathrm{pH}$ of the ground water samples during rainy season from Patan area was ranged from 5.6-6.3 and the conductivity, hardness and ammonia for all samples were found to lie within WHO permissible level. The value for chloride and ammonia ranged from $60-288 \mathrm{mg} / \mathrm{L}$ and $>1.5 \mathrm{mg} / \mathrm{L}$, respectively. Similarly, in summer seasons, $\mathrm{pH}$ and temperature ranged from $5.9-6.7$ and $21-22.7^{\circ} \mathrm{C}$. The values for conductivity and hardness were found within the WHO limit, and chloride, ammonia, total iron, calcium and magnesium ranged from 50$324 \mathrm{mg} / \mathrm{L}, 0.13>1.5 \mathrm{mg} / \mathrm{L},<0.05-5.15 \mathrm{mg} / \mathrm{L}, 33.6-83.2 \mathrm{mg} / \mathrm{L}$ and $4.38-35.57 \mathrm{mg} / \mathrm{L}$, respectively ${ }^{8}$.

For the removal of heavy metal ions from waters, ion exchange methods, chemical precipitation, electro-deposition, filtration and adsorption are used. Because of the global environmental issues, the necessity for adsorbent materials and their fields of application are increasing. This situation makes the development of high performance adsorbents a matter of considerable interest and importance ${ }^{9}$. Low cost adsorbents are of immense importance for the treatment of heavy metal pollutants. Chemical contaminants at low concentrations are difficult to remove from water. Reverse osmosis and other methods become inefficient when contaminants are present in trace concentrations. The process of adsorption is one of the few alternatives available for such situations. A number of adsorbent materials have been studied for their capacity to remove heavy metals, including activated carbon, activated alumina, ion exchange resins, crushed coals, chitosen, polysaccharide, peat moss, sand fitters, ash of paper, waste disposal of sugarcane \& orange wastes etc. Some of these materials, such as ion exchange resins are effective but expensive and have higher selectivity for alkali and alkaline earth ions than for heavy metal ions ${ }^{10}$; and others, such as coal and straw, are inexpensive but effective mostly in cases of negative ions contaminations. Activated carbon is very effective in removing heavy metals, but is readily soluble under extreme $\mathrm{pH}$ conditions ${ }^{11}$.

Removal of iron \& manganese from aqueous solution using palm fruit hunch and maize cob were studied. The adsorption capacities for iron ions on palm fruit hunch \& maize cob were in the $57-80 \%$ range \& for the $\mathrm{Mn}$ ion in the $50-79 \%$ range for initial concentration between $1 \mathrm{ppm}$ and $10 \mathrm{ppm}$. With mixtures of both metal ions in removal of iron ions from the mixture was in the 54-79\% range and for the $\mathrm{Mn}$ ion in the 54-76\% range ${ }^{12}$.

In the present study, the ground water samples from 10 different sites were collected and the selection criteria for the sites of water collection were population density and much more use of ground water in particular area. The reports of the ground water analysis suggested that the main contamination of ground water of Kathmandu is ammonical nitrogen and iron. The ammonical nitrogen can be reduced by simply aeration technique but we need to focus our attention for iron removal from ground water. Thus, three categories of adsorbents were used in the present study for iron removal which were (a) having higher contents of $\mathrm{Ca}^{2+}$ ion which can exchange with iron such as crab's shell powder, chemically treated silica stone powder, chemically treated lime stone powder, pure $\mathrm{CaCO}_{3}$ and hen's eggshell powder, (b) having higher content of carbon which can adsorb heavy metal ions in its large surface area and microporous mesoporus pores such as charcoal and sugarcane waste ash and (c) having higher content of aluminum and thus responsible for heavy metal ions precipitation such as alum were used. 


\section{EXPERIMENTAL}

\subsection{Collection and Preservation of Samples}

This study was conducted only in Kathmandu district. The ten different sampling sites where the population was relatively dense were chosen for the examination. The sampling locations are shown in Fig. 1. Among the ten ground water samples, five were from deep tube wells, four from shallow tube wells and one from hand pump. The samples were named as follows:- S-1 for Guheswori, S-2 for Baneshwor, S-3 for Kalanki, S-4 for Maharajgunj, S-5 for Koteshwor, S-6 for Tri-Chandra Campus, S-7 for Thankot, S-8 for Lainchour, S9 for Balaju and S-10 for Balambu.

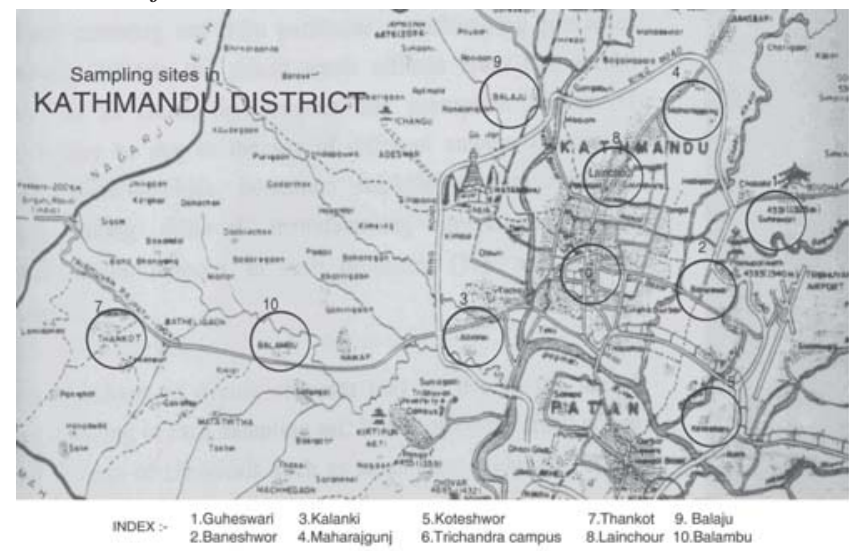

Fig-1: Ground water samples collected from various sites of Kathmandu district.

Most of the reagents used in the present study were of the analytical grade. All the experiments related to ground water were performed according to the methods described in "Standard Method for the Examination of Water and Waste water” 1998 (20th Edition, APHA, AWWA, and WEF) ${ }^{13}$.

The effluent samples were collected in $100 \mathrm{ml}$ plastic bottles. These bottles were thoroughly cleaned by $8 \mathrm{M}$ nitric acid, followed by repeated washing with distilled water and dried overnight. After the collection of samples, the appearance and temperature of water samples were recorded in the field \& the bottle mouths were immediately sealed. The $\mathrm{pH}$ of all samples was recorded using pH meter (Elico LI 613, India). The general physical appearance of water samples was recorded by the unaided eye.

After the $\mathrm{pH}$ measurement, samples were preserved immediately after sampling by acidifying with concentrated nitric acid (1.5 ml. conc. $\mathrm{HNO}_{3} / \mathrm{L}$ water sample). No filtration of samples was done before or after the preservation of acid.

All the ten samples were digested by concentrated $\mathrm{HNO}_{3}$ acid. First of all, $100 \mathrm{ml}$ of sample water was taken in a $250 \mathrm{ml}$. conical flash. Then, $5 \mathrm{ml}$. of conc. $\mathrm{HNO}_{3}$ was added to it. The solution mixture was boiled until the volume was reduced to about 10 to $20 \mathrm{ml}$. Continued heating \& addition of conc. $\mathrm{HNO}_{3}$ was done as necessary until digestion was completed as shown by a light colored clear solution. Care must be taken during digestion so that sample may not dry. Flask was washed with distilled water and filtered. The filtrate was transferred to a $100 \mathrm{ml}$ volumetric flask and cooled and diluted to mark by distilled water and mixed thoroughly ${ }^{13}$. The digestion by concentrated $\mathrm{HNO}_{3}$ was done for all the ten ground water samples.

\subsection{Preparation of Standard Solutions}

Blank solution was prepared from distilled water and acidified with 2-3 drops of conc. $\mathrm{HNO}_{3}$ solution. Potassium solutions of $10,30,50$ and $100 \mu \mathrm{g} / \mathrm{L}$ were prepared from oven dried $\left(110^{\circ} \mathrm{C}\right) \mathrm{KCl}$. Sodium solutions of $10,30,50$ and $100 \mu \mathrm{g} /$ $\mathrm{L}$ were prepared from oven dried $\left(140^{\circ} \mathrm{C}\right) \mathrm{NaCl}$. Both sodium and potassium solutions were acidified with $1 \mathrm{ml}$ conc. $\mathrm{HNO}_{3}$ solution. The estimation of concentrations of lead in ground water samples was done at Nepal Bureau of Standards and Metrology by using 1, 2, 3 and $4 \mathrm{mg} / \mathrm{L}$ lead solutions as standard lead solutions. First these solutions were aspirated and later acid digested ground water solutions. Cadmium solutions of 1, 2, 3 and $4 \mathrm{mg} / \mathrm{L}$ were prepared from oven dried $\left(110^{\circ} \mathrm{C}\right) \mathrm{CdCl}_{2}$ by dissolving in acidified distilled water. Stock Zinc solution was prepared by dissolving 0.10 gm zinc metal in $20 \mathrm{ml} \mathrm{N} / 2 \mathrm{HCl}$ and diluted to $1000 \mathrm{ml}$ with distilled water. From this solution 1, 2, and $3 \mathrm{mg} / \mathrm{L}$ zinc solutions were prepared. Stock Iron solution was prepared by dissolving $0.10 \mathrm{gm}$ iron metal powder in a mixture of $10 \mathrm{ml} \mathrm{N} / 2 \mathrm{HCl}$ and 8 $\mathrm{ml}$ conc. $\mathrm{HNO}_{3}$ and diluted to $1000 \mathrm{ml}$ with distilled water. From this stock solution 5, 10, 20, and $30 \mathrm{mg} / \mathrm{L}$ solutions were prepared.

\subsection{Determination of Metal Ions Concentrations}

The elemental analysis was carried out on a Perkin Elmer Aanalyst -100 atomic absorption spectrophotometer with a single-slit burner, a pneumatic nebulizer, and coded hollowcathode lamps. For sodium and potassium working mode was atomic emission and hence no lamps were required whereas for lead (wavelength $283.3 \mathrm{~nm}$ ), iron (wavelength $248.3 \mathrm{~nm}$ ) zinc (wavelength $213.9 \mathrm{~nm}$ ) and cadmium (wavelength 228.8 $\mathrm{nm}$ ), the working mode was atomic absorption and thus coded HCLs were used.

In case of coded HCL, default condition was used and three replicates reading were taken for each sample. The integration time was taken as 0.10 second. By aspirating standard solutions followed by aspiration of acid digested groundwater solutions, concentration of all samples were determined ${ }^{13}$.

\subsection{Preparation of Adsorbent for Iron}

Adsorbents such as crab's shell powder, silica stone powder, hen's eggshell powder and limestone powder were prepared after treated with $0.1 \mathrm{M} \mathrm{HCl}$ and $0.1 \mathrm{M} \mathrm{NaOH}$. The adsorbents such as pure $\mathrm{CaCO}_{3}$ and alum were used directly after pulverizing into smaller particle sizes. All these adsorbents were used for adsorption experiments under the following conditions: Temperature $=21^{\circ} \mathrm{C}$; Stirring time $=6$ hours; by using certain initial concentration of iron solution. The sample/solution ratio was taken as $0.002 \mathrm{~g} / \mathrm{ml}$. As hen's eggshell powder shows greater adsorption capacity for iron than others, so it was used for the present work. 
The hen's eggshell was first washed with distilled water and then dried in an oven at $125^{\circ} \mathrm{C}$. The raw sample was pulverized using mortar and pestle. Powdered hen's eggshell of definite particle size was further purified by first boiling in $0.1 \mathrm{~N} \mathrm{HCl}$ for three hours. The solution was decanted and the residue was treated further by boiling in $0.1 \mathrm{~N} \mathrm{NaOH}$ for another three hours. The purified samples were washed several times and were soaked in distilled water. Soaking of hen's eggshell resulted in swelling which results in more reaction sites in the adsorbent material. Later the samples were dried in an oven at $100^{\circ} \mathrm{C}$.

\subsection{Sorption Properties of the Resultant Samples}

A stock solution of the adsorbate containing $1000 \mathrm{mg} / \mathrm{L}$ of iron ions was prepared using $0.100 \mathrm{gm}$ of iron powder as done to prepared standard solutions of iron previously. From the stock solution, aliquots containing different concentrations viz. 5, 10, 15, 20, 25, 30, 35,40, 45 and 50 mg/L of iron ions were prepared and their initial concentrations were noted using AAS. A sample adsorbate of each concentration $\{$ taken as $25 \mathrm{ml}$ \} was mixed with $0.1 \mathrm{gm}$ of Hen's eggshell powder and the mixtures were agitated in a mechanical shaker for six hours. After this, solution was filtered and the final concentrations of iron ion were evaluated ${ }^{14}$.

The percentage removal (\%) and adsorbed Fe ions (mg/g) were calculated using the following formulae.

$$
\begin{aligned}
& \text { Percentage removal }=\frac{\left(C_{i}-C_{e q}\right) \times 100}{C_{i}} \\
& \text { Adsorbed Fe }(\mathrm{mg} / \mathrm{g})=\frac{\left(C_{i}-C_{e q}\right) \times V}{1000 M}
\end{aligned}
$$

Where $\mathrm{C}_{\mathrm{i}}$ and $\mathrm{C}_{\mathrm{eq}}$, are the initial concentration and equilibrium concentration $(\mathrm{mg} / \mathrm{L}), \mathrm{V}$ and $\mathrm{M}$ are volume $(\mathrm{ml})$ and amount of sample (g) respectively ${ }^{9}$.

\section{RESULT AND DISCUSSION}

\subsection{Physico-Chemical Analysis of Water samples}

The physical and chemical parameters of water samples analyzed from various groundwater sources in Kathmandu are given in Table 2. (a) Physical Appearance: Most of the samples were dirty and colored. Sample from site S-8 was milky. It may be because of certain gases that were present in water such as $\mathrm{CO}_{2}$ and etc. Groundwater samples from site S-1 and S-2 were clear. Samples from sites S-3, S-4, S-5, S-6, S-7, S-9 and S-10 were cleared when pumped from a well but became reddish-brown colored after standing in contact with air. This may be due to the oxidation of $\mathrm{Fe}(\mathrm{II})$ to $\mathrm{Fe}(\mathrm{III})$ in presence of air. This $\mathrm{Fe}(\mathrm{III})$ oxide is insoluble and hence precipitation occurred. When excessive concentrations of dissolved iron are found in ground water it is always in the reduced ferrous form.

(b) Temperature: The temperature of ground water samples ranged from $20.1^{\circ} \mathrm{C}$ to $23.1^{\circ} \mathrm{C}$. The minimum and maximum temperatures recorded were $20.1^{\circ} \mathrm{C}(\mathrm{S}-6)$ and $23.1^{\circ} \mathrm{C}(\mathrm{S}-10)$.

(c) The $\mathbf{p H}$ : The $\mathrm{pH}$ values for water samples ranged from 6.5 to 7.2, which lies within permissible guideline value recommended by WHO. Only two samples S-2 and S-9 were found slightly basic whereas rests of all were acidic in nature.

Some of the physical parameters of ten different samples from Kathmandu district are listed in Table 1.

Fig. 2 shows the variation on the amount of Fe present in the different underground water samples of Kathmandu district. From the graph, it is clear that the amount of Fe is the maximum in Tri-Chandra Campus (S-6) and minimum in Baneshwor (S2). Some of metal ions were found to be out of detectable limit of the instrument.

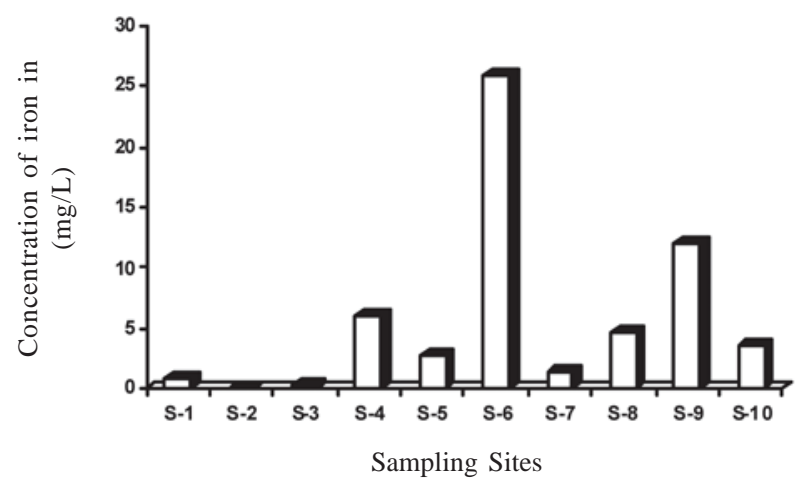

Fig-2: The variation of Fe ion concentration in different sampling sites of Kathmandu.

\begin{tabular}{|c|c|c|c|c|c|c|c|c|c|c|}
\hline Sample & Water Sourc. & Appearance & Temp. & $p H$ & $K$ & $\mathrm{Na}$ & $P b$ & $C d$ & $Z n$ & $\mathrm{Fe}$ \\
\hline Units & & & $\left({ }^{\circ} \mathrm{C}\right)$ & & $\mu \mathrm{g} / \mathrm{L}$ & $\mu \mathrm{g} / \mathrm{L}$ & $\mathrm{mg} / \mathrm{L}$ & $\mathrm{mg} / \mathrm{L}$ & $\mathrm{mg} / \mathrm{L}$ & $\mathrm{mg} / \mathrm{L}$ \\
\hline WHO standard & & & & $6.5-8.5$ & - & $2 \times 10^{5}$ & 0.10 & 0.003 & 3.0 & 0.3 \\
\hline S-1 & DTW & Clear & 21.2 & 6.9 & 6.9 & 30.2 & 0.15 & nd & 0.4 & 0.9 \\
\hline S-2 & HP & Clear & 20.8 & 7.1 & 27.0 & 32.9 & nd & nd & nd & 0.1 \\
\hline S-3 & SW & Dirty & 22.9 & 6.8 & 53.3 & 99.5 & nd & nd & nd & 0.2 \\
\hline S-4 & DTW & Dirty & 20.5 & 6.5 & 2.9 & 18.8 & nd & nd & nd & 6.0 \\
\hline S-5 & SW & Dirty & 22.0 & 6.5 & 25.9 & 30.3 & nd & nd & 0.2 & 2.8 \\
\hline S-6 & DTW & Dirty & 20.1 & 6.9 & 8.8 & 22.3 & nd & nd & 0.4 & 25.8 \\
\hline S-7 & SW & Dirty & 22.1 & 6.8 & 5.8 & 23.9 & nd & nd & nd & 1.5 \\
\hline S-8 & DTW & Milky & 20.4 & 6.9 & 7.1 & 34.8 & nd & nd & nd & 4.6 \\
\hline S-9 & SW & Dirty & 20.5 & 7.2 & 14.6 & 63.8 & nd & nd & 0.4 & 11.9 \\
\hline S-10 & SW & Dirty & 23.1 & 6.5 & 12.0 & 71.8 & nd & nd & nd & 3.5 \\
\hline
\end{tabular}

Table 1: Physico-chemical analysis of under groundwater samples of Kathmandu district

World Health Organization (WHO) Guideline value (1984); DTW: -Deep Tube Well; SW: - Shallow Well and nd: - not detectable 
Table 2: Langmuir and Freundlich parameters in the adsorption for iron by hen's eggshell powder

\begin{tabular}{|c|c|c|c|c|c|c|}
\hline \multirow{2}{*}{ Adsorbent } & \multicolumn{3}{|c|}{ Langmuir parameters } & \multicolumn{3}{c|}{ Freundlich parameters } \\
\cline { 2 - 7 } & $\mathbf{Q}_{\mathbf{0}}(\mathbf{m g} / \mathbf{g})$ & $\boldsymbol{b}(\mathbf{L} / \mathbf{m g})$ & Corr. coeff. & $\mathbf{K}_{\mathbf{f}}$ & $\boldsymbol{n}$ & Corr. coeff. \\
\hline Hen's egg shell powder & 1.80 & 0.28 & 0.99 & 0.85 & 5.52 & 0.82 \\
\hline
\end{tabular}

\subsection{Fe ions Adsorption Experiments}

The sorption of iron ion from water samples was carried out with various adsorbent prepared previously. The initial concentration of iron ion was varied from 5 to $50 \mathrm{mg} / \mathrm{L}$. The adsorption of metal ions onto adsorbent sample is considered to be rather complicated, and usually consists of more than one mechanism (adsorption, ion exchange, surface precipitation, etc. $)^{15}$. The isotherm data for iron adsorption by adsorbents were analyzed in the light of Langmuir and Freundlich modes of adsorption ${ }^{16}$. Fig. 3 show that the adsorbent prepared from hen's eggshell powder has a higher iron sorption capacity than other adsorbents. Therefore, this adsorbent is used for further study. The superior adsorption capacity of the hen's eggshell powder than other adsorbents was might be due to the porous structure of the eggshell, presence of natural polysaccharide in its membrane, which also helps to adsorb heavy metal ions. As eggshell is calcium richer substance, therefore, it became easier for cation exchange reaction.

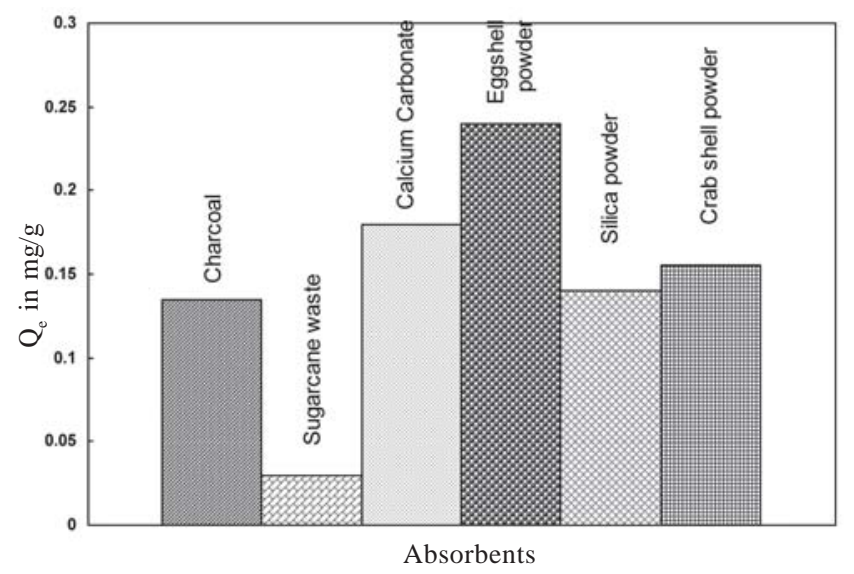

Fig-3: The Fe adsorption capacity of different adsorbents.

\subsection{Effect of Initial Concentration on Adsorption Rate}

The effect of the initial iron concentration on the extent of adsorption was studied and found that the dependence of the system on the concentration factor is explained by low iron to hen's eggshell powder ratio at lower concentrations. However, at higher concentrations the available sites of adsorption becomes fewer and hence the percentage removal of iron is dependent upon the initial concentration. Thus the adsorption rate increased with an increase in the concentration ${ }^{14}$. Thus at higher concentrations multilayer adsorption also occurred. Thus, both Langmuir and Freundlich isotherms were found to fit the biosorption data ${ }^{15}$.

\subsection{Adsorption Isotherms}

The iron ion sorption behavior can be simulated by the use of mathematical equations. In this paper, the Langmuir and Freundlich models were used to simulate the isotherm data.

(a) Langmuir isotherm: The Langmuir model assumes that the sorption of metal ion occurs on a homogenous surface by monolayer adsorption with no interaction between adsorbed ions. The model takes the following form:

$$
\frac{C e}{Q e}=\left(\frac{1}{Q o}\right) C e+\left(\frac{1}{Q o . b}\right)
$$

where $\mathrm{C}_{\mathrm{e}}$ is the equilibrium concentration $(\mathrm{mg} / \mathrm{L}), \mathrm{Q}_{\mathrm{e}}$ the amount adsorbed at equilibrium (mg/L), $\mathrm{Q}_{0}(\mathrm{mg} / \mathrm{g})$ and $b(\mathrm{~L} /$ mg) are the Langmuir constants related to the adsorption capacity and energy of adsorption respectively.

(b) Freundlich isotherm: The Freundlich model assumes that the sorption of metal ion occurs on a heterogeneous surface by monolayer adsorption. The model is described by the following equation:

$\log _{e}=\log _{f}+\left(\frac{1}{n}\right) \log C_{e}$

where, $\mathrm{K}_{\mathrm{f}}$ and $n$ are the Freundlich constants.

Langmuir and Freundlich parameters were obtained by plotting $\mathrm{C}_{\mathrm{e}}$ versus $\mathrm{C}_{\mathrm{e}} / \mathrm{Q}_{\mathrm{e}}$ and $\log \mathrm{C}_{\mathrm{e}}$ versus $\log \mathrm{Q}_{\mathrm{e}}$ respectively and presented in Table 2.

With the help of the data obtained from Langmuir and Freundlich parameters from Table 2, the adsorption isotherms for Langmuir and Freundlich were drawn and shown in Fig. 3 (Solid line for calculated curve for Langmuir adsorption isotherm and dotted curve for Freundlich isotherm). The correlation coefficient values together with the isotherm plots indicated that the adsorption mechanism is of the monolayer and Langmuir isotherm of the L-type was found to have better fitting to the observed results according to the general classification of adsorption isotherms from aqueous solutions ${ }^{17}$.

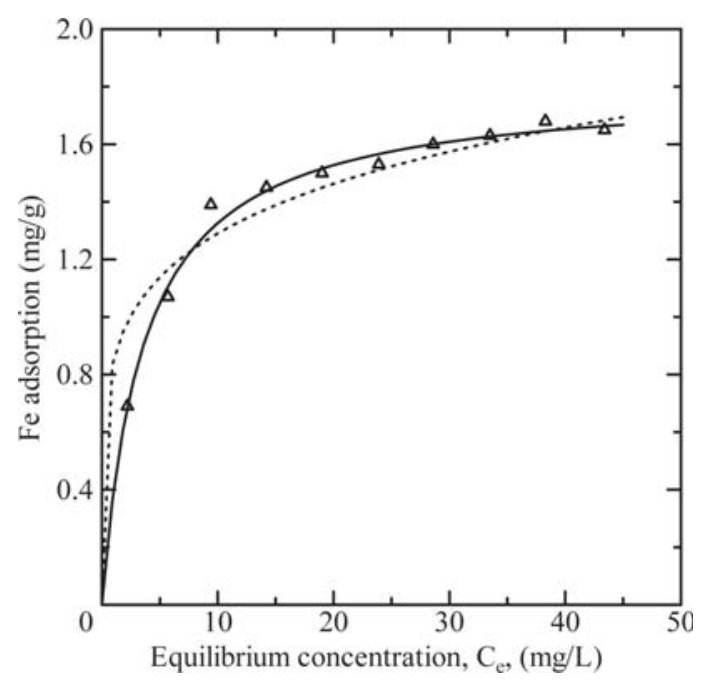

Fig-3: Adsorption isotherm for the adsorption of Fe from the adsorbent prepared from hen's eggshell powder (Solid line for calculated curve for Langmuir adsorption isotherm and dotted curve for Freundlich isotherm). 


\section{CONCLUSION}

The study shows that most of the groundwater samples from Kathmandu are contaminated with iron whereas sodium, zinc, cadmium, lead and potassium were within WHO permissible limit. Presence of iron in higher concentration might have been due to geological condition.

The possibilities of using hen's eggshell as an adsorbent to remove heavy metal ions from wastewater have been studied and discussed for the particular case of aqueous solution of iron. The hen's eggshell has demonstrated a superior adsorption capability compared with more conventional adsorbent materials. The adsorption isotherm was in better agreement with the Langmuir model than the Freundlich one. The value of Langmuir constant $\left(\mathrm{Q}_{0}\right)$ was found to be 1.80 and Freundlich exponent $n$ greater than one for iron metal confirmed the adsorption of metals onto hen's eggshell. Thus, hen's eggshell seemed to be a useful alternative sorbent material for the reduction of environmentalas well as aquatic pollution.

\section{REFERENCES}

1. ENPHO Magazine. 2004. Ground Water Quality of Kathmandu Valley. Environment and Public Health Organization, Nepal.

2. Mays, I.W. 1996. Water Resources Handbook. McGraw-Hill, India.

3. Miyake, M., Komarneni, S. \& Roy, R. 1988. Cement and Concrete Research. 18: 485.

4. Jha, V.K., Kameshima, Y., Nakajima, A., Okada, K. \& MacKenzie, K.J.D. 2006. Journal of Environmental Science \& Health. A-111: 703.
5. Srivastava, S.K., Gupta, V.K. \& Mohan, D. 1997. Journal of Environmental Engineering. 123: 461.

6. Pradhananga, T.M., Thapa, A., Sharma, U., Shahi, R.R. and Shrestha, S. 1993. Journal of Nepal Chemical Society. 12: 55.

7. Zouboulis, A.I. \& kydros, K.A.1993. Journal of Chemical Technology and Biotechnology. 58: 95.

8. Sharma, A.P. 1986. A report Submitted to National Committee for Man and Biosphere, Nepal.

9. Jha, V.K., Kameshima, Y., Okada, K. and MacKenzie, K.J.D. 2004. Separation and Purification Technology. 40: 209.

10. Jha, V.K., Kameshima,Y., Nakajima, A., Okada, K. \& MacKenzie, K.J.D. 2005. Journal of Hazardous Materials. B-123: 281.

11. Mohammad, N., Parr, J., Smith, M.D. and Wheatley, A.D. 1998. Sanitation and Water for All. 24th WEDC Conference, Islamabad, Pakistan.

12. Sum, K.S. 2005. Journal of the Acoustical Society of America. 117: 486.

13. Clesceri, L.S., Greenberg, A.E. and Eaton, A.D. 1998. Standard Methods for the Examination of Water and Waste Water $\left(20^{\text {th }}\right.$ edition) APHA, AWWA, WEF, Monrovia, USA.

14. Karthikeyan, G., Andal, N.M. and Anbalagan, K. 2005. J. Chem. Sci., 117: 663.

15. Solari, P., Zouboulis, A.I., Matis, K.A. \& Stalidis, G.A. 1996. Sep. Sci. Technol. 31(8): 1075.

16. A1-Degs, Y.S., Tutunji, M.F. \& Baker, H.M. 2003. Clays Clay Miner. 38: 501.

17. Giles, C.H., McEwan, T.H., Nakhwa, S.N. \& Smith, D. 1960. J. Chem. Soc. 3973: 3993. 